\title{
Anne MORELLI et Eliane GUBIN (textes réunis et coordonnés par), Pour une histoire européenne des femmes migrantes. Sources et méthodes, Sextant, revue du Groupe interdisciplinaire d'Études sur les Femmes, Université libre de Bruxelles, n² 21-22, 2004, 302 pages.
}

Linda Guerry

\section{(2) OpenEdition Journals}

\section{Édition électronique}

URL : https://journals.openedition.org/clio/7043

DOI : 10.4000/clio.7043

ISSN : 1777-5299

\section{Éditeur}

Belin

Édition imprimée

Date de publication : 1 novembre 2007

Pagination : 232-264

ISBN : 978-2-85816-940-5

ISSN : 1252-7017

\section{Référence électronique}

Linda Guerry, «Anne MORELLI et Eliane GUBIN (textes réunis et coordonnés par), Pour une histoire européenne des femmes migrantes. Sources et méthodes, Sextant, revue du Groupe interdisciplinaire d'Études sur les Femmes, Université libre de Bruxelles, n²1-22, 2004, 302 pages. », Clio. Femmes, Genre, Histoire [En ligne], 26 | 2007, mis en ligne le 15 avril 2008, consulté le 23 avril 2022. URL : http:// journals.openedition.org/clio/7043; DOI : https://doi.org/10.4000/clio.7043

Ce document a été généré automatiquement le 23 avril 2022

Tous droits réservés 


\title{
Anne MORELLI et Eliane GUBIN (textes réunis et coordonnés par), Pour une histoire européenne des femmes migrantes. Sources et méthodes, Sextant, revue du Groupe interdisciplinaire d'Études sur les Femmes, Université libre de Bruxelles, $n^{\circ} 21-22,2004,302$ pages.
}

\author{
Linda Guerry
}

1 Le volume 21-22 de la revue belge Sextant regroupe 14 contributions en français de chercheuses et chercheurs de divers centres d'études et universités européens. Il s'agit de la publication des actes d'un colloque international organisé en mai 2004 par le Groupe d'Étude pour l'Histoire de l'Immigration et le Groupe interdisciplinaire d'Études sur les Femmes de l'Université libre de Bruxelles.

2 Alors que l'histoire des femmes immigrantes est déjà explorée outre-Atlantique depuis les années 1980, dans plusieurs pays européens elle constitue un nouvel objet de la recherche historique. Mais comme le soulignent Anne Morelli et Éliane Gubin dans leur introduction, l'invisibilité de la participation des femmes dans les migrations du passé reste importante et cette publication au titre revendicatif contribue à mettre au jour cette « histoire souterraine» (p. 7). Les migrations abordées sont toutes centrées sur l'Europe mais la publication fait partie d'un projet à moyen terme de mise en réseau de chercheuses et chercheurs travaillant sur l'histoire des migrations féminines « ̀̀ l'intérieur de l'Europe », mais aussi « à partir de l'Europe » et « vers l'Europe » (p. 8). 
3 L'approche choisie est celle de la méthodologie par l'étude de cas. Les femmes migrantes n'échappent pas au « silence des sources » relatif à l'histoire des femmes en général, mais les contributions montrent qu'il n'est pas pour autant impossible d'écrire l'histoire des femmes migrantes. Les sources classiques de l'histoire de l'immigration sont fréquemment insuffisantes pour l'étude des femmes (contribution d'Anastasia Antiochos), mais Jacques Gillen souligne que la «transparence » des femmes migrantes résulte bien souvent du regard de l'historien: certaines sources sont en effet plus riches qu'on ne le supposait (p. 33). La contribution de Sarah Vanessa Losego, qui, à partir d'un dossier de naturalisation, retrace trois histoires parallèles d'une même femme, montre efficacement les multiples usages possibles de ce type de sources administratives : parcours biographiques, mais surtout regard administratif porté sur les femmes candidates à la naturalisation, et usages par les postulantes de l'option de la naturalisation.

4 La question du travail des femmes migrantes est largement traitée dans le volume. Pour la période 1800-1950, les migrations temporaires des nourrices italiennes et des domestiques allemandes sont présentées par Daniela Perco et Mareike König. Monika Mattes traite du cas des «travailleuses immigrées» en Allemagne de l'Ouest (1955-1973), aspect moins connu du travail des femmes migrantes alors qu'elles constituaient jusqu'à $30 \%$ du nombre total des ouvriers étrangers en RFA; l'auteure montre que la catégorie de genre a joué un rôle décisif dans la politique de recrutement de l'agence fédérale pour l'emploi et du patronat ouest-allemand. La question du genre des politiques d'immigration de main-d'œuvre est posée plus largement par Frank Caestecker dans l'ébauche d'une synthèse sur la recherche dans ce domaine pour l'Europe occidentale. Dans sa contribution sur les émigrantes espagnoles (seconde partie du XXe siècle), Ana Fernandez Asperilla explore le rôle de la formation, de la qualification professionnelle et de l'éducation des femmes en Espagne dans la situation des immigrantes sur le marché du travail du pays d'accueil.

5 Outre la question du travail, d'autres thèmes sont explorés : le rôle des femmes dans les choix résidentiels des migrants (le cas des Portugais par Carolina Leite), la protection des migrations féminines, qui est traitée dans deux contributions (par Anne Summers et Valérie Piette); enfin, le cas des "migrantes-militantes", par une contribution d'Anne Morelli et Jean-Philippe Schreiber sur Yvonne Jospa, "juive immigrée en Belgique, communiste et militante anti-raciste ». À noter que l'ouvrage ne traite pas seulement des femmes migrantes mais aussi de celles restées au pays. Le cas des Italiennes au XIXe siècle, qui fait l'objet de la contribution de Bruna Bianchi, pointe les conséquences du départ des hommes sur la vie des femmes et montre le rôle de celles qu'on appelait « veuves blanches » dans l'accomplissement du projet migratoire.

6 Autant de thématiques qui rendent l'ouvrage quelque peu dispersé, mais qui ne peuvent qu'encourager des recherches sur la part féminine de l'histoire européenne des migrations et motiver une approche genrée du phénomène migratoire. 